A draft of Willinsky, J. (2002). Education and Democracy: The Missing Link May Be Ours. Harvard Educational Review, 72(3), 367-392 (as HER does not grant permission to post the published paper).

\title{
Democracy and Education: The Missing Link May Be Ours John Willinsky
}

Much has changed since Dewey (1916) first laid out in Democracy and Education his vision of the US as a state of perpetual inquiry where citizens are engaged in sharing educational experiences. Changes for the good include extending suffrage to women and people of color, rising educational attainment, the successful challenging of racial segregation in the courts, and the recognition of cultural diversity through mulitcultural initiatives. On the other hand, American voter participation has declined, particularly since the 1960s; civic involvement, not to mention bowling-league membership, is down (Putman, 2000); corporate control of the media has increased, as has the media's political influence (Bagdikian, 2000; McChesney, 1999); and affirmative action measures, which were showing positive educational effects (Bowen and Bok, 1998), are being challenged and blocked (Dworkin, 2001).

Against this century-long backdrop, we now face a rather different order of political change with the rapid development of the Internet. Over the course of the last ten years, the Internet has opened a new world of information to the public. The increased access to information relates to every aspect of our lives and is on such a scale that it seems bound to alter the relationship between democracy and education. Whether the introduction of the Internet bears comparison with the revolution that Gutenberg initiated with his invention of moveable type and printer's ink, as Christine Borgman contends (2000), it seems to me far too early to say. While the political and educational impact of the printing press was centuries in the making, I think that we could do worse than be inspired by such historical analogies in our efforts to make sense of this new communication technology and to shape how it is used in this political and educational sense. Certainly, the Internet has already starting showing signs that it will reshape political participation and the way we are governed, with the emphasis in this new digital democracy on providing more powerful public access to information and officials (Alexander and Pal, 1998; Hague and Loader, 1999; Heeks (1999), and Wilhem, 2000)

One dramatic, if surprising, example of the Internet's democratic impact on public education and empowerment, in its broadest sense, is with public access to health information. The result has been that patients and their families now bring Web-based medical information to their doctors' offices, although they may not understand it well, nor is the information always reliable. However, it is the very availability of this information that is altering the nexus of power and knowledge in doctor-patient relationships - on the side of more empowering and democratic processes - as well as fostering more informative and educational visits for both parties. ${ }^{1}$ The technology is also

\footnotetext{
${ }^{1}$ The federally funded MEDLINEplus (http://medlineplus.gov/) provides an excellent example. For a discussion of changing doctor-patient relationships, see Freudenheim (2000, p. A1).
} 
being used to better inform people in a more traditional political sense, as governments in the developed world continue to expand new online information services. These services increase citizens' abilities to tap into their rights and entitlements, to more thoroughly explore policies and programs, and to inundate politicians with their views and positions by email. $^{2}$

Scholarly publishing outside the life sciences has also begun to contribute to this greater world of public information, with electronic journals and research websites in many disciplines providing "open access" to their articles and other scholarly resources. Scientists have created, often with government support, substantial open-access indexes and abstract services for research, as well as many full-text archives that can be freely accessed by their colleagues and students globally. ${ }^{3}$ These new open-access systems still offer only partial, often overlapping, coverage of their respective fields of study. As things currently stand, most electronic journals, including those published by scholarly societies, as well as commercial academic publishers, still require a library or individual subscription to access them. But there is a growing open-access movement afoot among researchers, perhaps best indicated by the nearly 30,000 signatures from scientists in 177 countries on the Public Library of Science petition calling for open access to scientific research: "We believe that the permanent, archival record of scientific research and ideas," the Public Library of Science website states, "should neither be owned nor controlled by publishers, but should belong to the public, and should be made freely available. We support the establishment of international online public libraries of science that contain the complete text of all published scientific articles in searchable and interlinked formats."4

Those who have signed have agreed to submit to, review for, and edit only those journals that, the website goes on to say, "grant unrestricted free distribution rights to any and all original research reports that they have published, through PubMed Central and similar online public resources, within six months of their initial publication date." This determination to make open and complete access to scientific knowledge available to medical students in Tanzania, high school teachers in Latvia, bio-chemists in Vietnam, as well as community college students in Montana, represents exactly the sort of ideal for scholarly publishing on a global scale that I hold to be part of the Internet's great democratic promise.

Such moves have been supported by the Open Archives Initiative, which began in 1999, and has developed standards that enable globally distributed research databases to

\footnotetext{
${ }^{2}$ For example, in British Columbia, "InfoSmart is the B.C. government's strategic framework to improve the way it works and delivers services to the public using information technology" (http://www.ista.gov.bc.ca/InfoSmart.htm). In the U.S., members of Congress received 80 million emails last year from constituents (Congress Struggles, 2001).

${ }^{3}$ The federally funded PubMed, for example, contains 11 million citations with full-text access to 1,800 journals (http://www.ncbi.nlm.nih.gov/entrez/query.fcgi); Paul Ginsparg's Los Alamos National Laboratory self-archiving e-print service will post 35,000 articles this year (htpp://arXiv.org); Stanford University Library's HighWire Press offers "one of the 2 largest free full-text science archives on earth" with over 250,000 free full-text articles and hundreds of thousands of pay-for-view articles (http://highwire.stanford.edu); and NEC's Researchindex (Lawrence, Giles, and Bollacker, 1999) provides access to 300,000 articles from among its four million citations (http://citeseer.nj.nec.com/cs). Also see, for example, William Y. Arms (2000) on open access principle and Peterson (2001), as well as Robert Cameron's (1997) proposal for a "freely available universal citation database,"

${ }^{4}$ Public Library of Science (http://www.publiclibraryofscience.org/).
} 
share a common indexing or metadata system so that they can be searched from a single source. ${ }^{5}$ More recently, the Budapest Open Access Initiative, funded by the Soros Foundation, has been launched to support and speed up processes that make "research articles in all academic fields freely available on the internet." 6 There is also the Open Knowledge Initiative, which is making MIT's course materials and course-ware freely available to the public, while the Public Knowledge Project, with which I work at the University of British Columbia, is developing free software to help journals and conferences around the globe publish open-access scholarly resources in an easily managed and well-indexed form. ${ }^{7}$

This emerging commitment among scholars to make the knowledge they create freely available is at the heart of my own call on the readers and editors of this journal to consider how turning educational research into a more accessible public resource can further the connection between democracy and education. While offering open access to all forms of scholarly research is certainly a global boon to students and faculty as well as curious minds everywhere, it has a special political significance for the social sciences, as this work bears directly on social policies, programs, and practices. If open access to research in the life sciences can create a more democratic and educational dynamic in doctor-patient relationships, then, as I have argued elsewhere, it is worth exploring across the social sciences (Willinsky, 2000). Here I am specifically asking researchers in the field of education to weigh the reasons why for greater public access to educational research is consistent with our understanding of our own work as fostering education and furthering democratic participation, just as it holds the love of learning and pursuit of knowledge that has driven so many of us in this line of work

But before I go any further let me make it clear that providing public access to educational research takes more than simply posting journal pages on the Web as if it were a giant bulletin board at the back of a great public classroom. It will require rethinking how our research works, once it is published, in terms of how it connects to a larger world. Although we have grown comfortable with stuffing the journal in our bookbag at the end of the day, to open it later at the kitchen table or in cafés, these low circulation, finely bound volumes are becoming harder to justify against their electronic counterparts. The print journal is proving too expensive for even well financed research libraries, let alone universities in developing nations, and it is nowhere near as efficient for locating specific ideas or following them across citations, for delving into the data or comparing related studies. ${ }^{8}$ This is a time, then, for rethinking the scholarly journal (rather than the book, I would hold, perhaps too nostalgically) in ways that relate to the scholarly and public qualities of our work.

This essay is not, however, about the technologies behind this new publishing medium. It is devoted to presenting the reasons why educational researchers should do more to foster open, better organized scholarly communication in the name of democracy

\footnotetext{
${ }^{5}$ Open Archives Initiative (http://www.openarchives.org).

${ }^{6}$ Budapest Open Access Initiative (http://www.soros.org/openaccess/).

${ }^{7}$ Open Knowledge Initiative (http://web.mit.edu/oki); the Public Knowledge Project (http://pkp.ubc.ca) is a federally funded research initiative at the University of British Columbia that seeks to improve the scholarly and public quality of academic research through innovative online environments.

${ }^{8}$ On the unsustainable costs of journals, see ARL Monograph and Serial Costs in ARL Libraries, 19861999 (http://www.arl.org), on the potential of electronic journal indexing systems, see Willinsky and Wolfson (2001)
} 
and education, rather than setting out technical solutions for achieving this organized openness. Still, I think it important to have some idea of what the actual systems at issue may entail. While "open access" publishing simply refers to providing free access to the complete contents of a journal or other resource, I believe something more is required if we are to truly improve the scholarly and public quality of research.

While a number of research groups are developing new publishing tools that improve the quality of access to academic journals, we at the Public Knowledge Project are currently working on four components of online publishing that we believe can significantly improve public access to research in areas such as education: (1) Online systems that enable less technically inclined faculty members to manage refereed journals, scholarly conferences, and other research sites that provide open access to complete studies with support for less experiences research readers, those with disabilities, and those without the latest technology; (2) Comprehensive, open access and automated indexing and archiving systems for online research, which allow readers to locate refereed research, dissertations, and other resources, and conduct fine-grained searches by, for example, research topic, sample characteristics, methodology, works cited, etc.; (3) Research support tools that enable readers to readily move from a given research study to its data set and research instruments, to related studies, reviews, overviews, and glossaries, and to relevant policy, program, and media materials in other databases; and (4) Open forums for researchers, professionals, policymakers, and the public to discuss educational issues, methods, and research agendas within the context of this body of research. ${ }^{9}$ You can see how this approach to open access publishing would support both the scholarly and public quality of research, as it not only extends public access but enhances faculty members' ability to track ideas, conduct peer reviews, and position their own work within the field.

I do not, however, want to underestimate what it means to ask journals to move from the paid-subscription world of print to open access publishing, even of the simplest sort. It is obviously a major step for a journal editorial team or professional association to undertake. At this point in the field of education, close to a hundred e-journals, including such notable titles as Educational Researchers and Teachers College Record, have been made freely available online, demonstrating that open access can be sustained in this field through institutional and association support. ${ }^{10}$ The software for running a peer review journal online is now being made freely available from a number of sources, including the Public Knowledge Project. The Association for Research Libraries, whose member libraries collectively spend $\$ 500$ million on journals, has understandably begun supporting projects in open access and non-profit online publishing, under the theme of "returning science to scientists." 11 One way of thinking about the financing of open access publishing is to see it as a matter of reallocating that $\$ 500$ million, moving some

\footnotetext{
${ }^{9}$ See the Public Knowledge Project (http://pkp.ubc.ca), and for the full range of electronic publishing tools being used by academic journals, see McKiernan (2001).

${ }^{10}$ See AERA's Electronic Journals in the Field of Education (http://aera-cr.ed.asu.edu/links.html).

${ }^{11}$ The Association of Research Libraries provides support through the Scholarly Publishing and Academic Resources Coalition (SPARC), where a listing of "publishing resources" can be found (http://www.arl.org/sparc/core/index.asp?page=h16). On new publishing economies, see Bailey (19962001) for a complete bibliography, Willinsky (2000a) for a funding model based on research library reallocation of funds and BioMed Central (http://www.biomedcentral.com) for open access supported by charging the authors a $\$ 500$ processing fee (waived for developing countries).
} 
portion of this money from the often excessive subscriptionrates of commercial publishers to more direct forms of support for online publishing by the leading research institutions, where a great number of the editors and scholarly association officers work. As we slowly wean ourselves away over the next decade from what is currently the unsustainable and inefficient publication of both print and electronic versions of the same journal, my hope is that we take advantage of these new technologies to explore with research libraries and professional associations an alternative political economy for academic knowledge that is based on open access publishing. At the very least, it would place this public good squarely within the public realm, in far more than a rhetorical sense.

As professors of education, we seem especially well-positioned to test the impact of this new communication medium on research's public role, especially as it might further the relationship between democracy and education. And while there are reasons enough to be skeptical about the educational impact of this new technology (Cuban, 2001; 1986), I do not think that this is the time to sit back and wait for things not to happen, not when the public presence of our own work is at issue. Insofar as we are committed to the value of research in informing policy and practice, we would do well to test whether these new publishing technologies can increase the contribution that research makes to the public's understanding of education, as well as contribute more to professional practices and policy decisions within education.

In asking researchers to consider new ways of testing the public value of their work, I am appealing to the experimental quality of democracy which was identified nearly two centuries ago by Alexis de Tocqueville as part of the very dynamic of the young American republic. De Tocqueville was inspired by his visit to America in 183132 to conclude that, "Democratic eras are periods of experiment, innovation, and adventure" (1969, p. 672, n.1). ${ }^{12}$ And as this democratic era has not ended, so this "great experiment," as de Tocqueville named it, should be sustained by innovation and adventure should be sustained today when democratic opportunities appear to present themselves. That there is something to democracy constantly in need of renewal and testing was also an operating premise of John Dewey. Consider how the final results are still not in on Dewey's own democratic experiment with education, for example, which continues to play out in progressive schools to this day. ${ }^{13}$ Across a wide rage of issues, we have yet to exhaust or fully explore the democratic possibilities of deliberation, justice, or equality, just as we continue to arrive over the course of our lifetimes at new understandings of what responsibility and freedom, community and cooperation mean within the democratic states within which we live. My premise is that at this point, given the possibilities for a better informed public, we need to push the democratic experiment by introducing new ways of accessing and utilizing existing sources of information bodies of knowledge that hold some promise of contributing to policymaking, personal decision-making, and other facets of democratic life.

\footnotetext{
12 Alexis de Tocqueville uses "experiment" many times in reference to American democracy, as is revealed by doing a search on the word with the online version of Democracy in America (http://xroads.virginia.edu/\%7EHYPER/DETOC/1_ch01.htm). There is also Abraham Lincoln: "Our popular Government has often been called an experiment" (1861).

${ }^{13}$ Dewey was prepared to re-evaluate his progressive education experiment, as he made clear in Education and Experience (1938) and as others continue to do (Ravitch, 2001).
} 
To that end, I devote the remainder of this paper to setting out a political philosophy of public access to scholarly publishing, as it pertains to the study of education. I argue that publishing systems that provide greater public access are likely to help us to better understand and extend Dewey's democratic theory of education, while enhancing the prospects of creating a more deliberative democratic state; and that they are in a good position to expand education's role within democracy, as well as increase the impact that education research has on practice, and provide an alternative source of information to the media's coverage of such issues as education. Think of these arguments as the first step in understanding how this new online publishing medium is going to test our fundamental assumption that education advances democracy. Think of these arguments as inviting the informed consent of the education research community, that its members might knowingly agree to participate in what may well prove to be the principal publishing experiment of this new medium in the years ahead. Now, experimentation with electronic publication is already well underway, and open access publishing has been tested and is now the channel of choice for physicists, who have had open pre-print archives for over a decade. ${ }^{14}$ Yet the real experimentation with systems that serve a world larger than the researcher's still await the participation of researchers, journal editors and scholarly societies, all of whom have now to make critical decisions about these technologies based on larger issues of social and political responsibility. It is time, I am suggesting, to think beyond the speed and convenience of our own desktop access to research, and to see access to this body of knowledge, in a field such as education, as far more of an experiment in what Dewey might call the communicative quality of democracy.

\section{Dewey, Deliberation, and Democracy}

The emphasis that I place on going public with our research follows from Dewey's concern for the particularly educational quality of democratic life. Can these new publishing systems be made to serve Dewey's democratic ideal - "to enable individuals to continue their own education" (1916, pp. 100-101)? Can they do so in ways that improve what is currently offered by newsstands, bookstores, the Web, and the media more generally? Can they extend education beyond formal schooling, which is Dewey's hope for democracy. For Dewey. education in a democracy represents a broadly based and lifelong embrace of learning: "Not only is social life identical with communication, but all communication (and hence all genuine social life) is educative" (1916, p. 5). While Dewey recognizes that "as societies become more complex in structure and resources, the need for formal and intentional teaching and learning increases," he seeks to work against "an undesirable split between the experience gained in more direct associations and what is acquired in school" (p. 9).

This interest in integrating learning into a greater part of life is at the heart of his contribution to progressive education, as well as central to his role as a public intellectual. To pursue Dewey's political philosophy through these publishing experiments is to see what they can do to integrate the systematic inquiry of research with "the experience gained in more direct associations." The question is whether greater access to research, as

\footnotetext{
${ }^{14}$ For the physics experiment in open access publishing, see the arXiv.org E-Print Archive (http:arXiv.org).
} 
well as its integration with other forms of knowledge, can enhance how people work and deliberate together.

At issue is what might be framed as the democratic quality of communication which is concerned with giving people a means to elaborate, substantiate, and challenge educational ideas, in this case, whether at the policy or school level. For Dewey, democracy is very much a matter of communication: "Men live in a community in virtue of the things they have in common; and communication is the way in which they come to possess things in common" (1916, p. 4). He also insists that "a democracy is more than a form of government; it is primarily a mode of associated living, of cojoint communicated experience" (p. 87). Although he says little of voting booths, candidate debates, or issue advertising, Dewey frequently refers to a basic level of communication among people, especially in this educational sense.

The communication of research, however, poses a special challenge to this democratic vision. It is not enough to simply open the doors of the research libraries a little wider. Dewey is concerned with people being overcome by the quantity and variety of knowledge they faced: "Man has never had such a varied body of knowledge in his possession before, and probably never before has he been so uncertain and so perplexed as to what his knowledge means, what it points to in action and consequences" (1988a, p. 249). Elsewhere, Dewey points to how the increasing complexity of the knowledge entailed in organizing modern society creates a fundamental democratic tension between expert and public control: "A class of experts is inevitably so removed from common interests as to become a class with private interests and private knowledge, which in social matters is not knowledge at all" (1988b, p. 365). To this Dewey adds the warning that "the world has suffered more from leaders and authorities than from the masses" (ibid). ${ }^{15}$

Rather than having people resign themselves to expert control, Dewey seeks to increase public access to the pertinent information. His own efforts to support an ill-fated newspaper entitled, Thought News, which sought to sell "the truth" came to naught in his early days in Michigan (Lagemann, 2000, p. 45). Yet he continued to hold to the idea that "a newspaper which was only a daily edition of a quarterly journal of sociology or political sciences would undoubtedly possess a limited circulation and a narrow influence. Even at that, however, the mere existence and accessibility of such material would have some regulative effect" (1988b, p. 349). This regulative effect would be on the side of a better informed public who would then be in a position to work with democracy's necessary class of experts rather than be governed by them. Such is the intellectual faith in systematic inquiry that drives our work. Dare we put it to the test?

Yet Dewey's careful reading of democracy also leaves me troubled with its emphasis on "associated living, of cojoint communicated experience" by which people "come to possess things in common" (1916, p. 87). This is one notion of democracy that has changed since Dewey first held that "in order to have a large number of values in

\footnotetext{
${ }^{15}$ As I discuss elsewhere (2000b), Dewey's stance on experts needs to be contrasted with the position of the popular political commentator Walter Lippmann who asked "whether it is possible for men to find a way of acting effectively upon highly complex affairs by very simple means," as people's "political capacity is simple" (1963a, p. 89-90). Lippmann saw the future lying in the hands of a technocracy of experts: "They initiate, they administer, they settle" (p. 92). Still Lippmann also held that "a democracy must have a way of life which educates the people for the democratic way of life" if only to make "people safe for democracy" (1963b, pp. 16, 26).
} 
common, all members of the group must have an equable opportunity to receive and take from others. There must be a large variety of shared understandings and experiences" (1916, p. 84). Instead, we see democracy as a means of governing those who do not necessarily share "a large variety of shared understandings and experiences." Dewey's sense of the nation as a shared experience tends to limit democracy's inclusiveness, just as his focus on the nation itself curtails a more global approach to this democratic exchange of understandings and experiences. ${ }^{16}$

In fact, one argument for going public with educational research is that it can bring into focus the level of diversity within which we already live. Researchers' own plurality of values, methods and understandings - which includes the very critique of such plurality (e.g., Schlesinger, 1992; Himmelfarb, 1995) - further supports a concept of democracy given to working with differences, rather than seeking a singular truth or vision of, for example, the good school. Democracy has far less to offer, after all, if people are assumed to already be in accord on all the major issues. This pluralism, then, provides the very reason why democratic citizens are necessarily interested in talking with, and learning from, each other. Increasing the public presence of a body of research that is itself pluralistic in its values, as well as given to representing the plurality within communities, can only help further what is seen by many as research's most important democratic task which is to assert the rights of those who are too often thought to fall outside the ken of shared concepts and culture. ${ }^{17}$

Certainly, academic culture has its own share of common values, from conventions of evidence to peer review, just as democracy requires the acceptance of a few basic principles of equality and justice. ${ }^{18}$ Yet within academic culture, such shared values are tempered by an ethos of critique, as well as a championing of the disenfranchised. It may be, then, that this body of research can afford the public not only a greater means of understanding how we live with differences, but a way of talking about that life which goes beyond Dewey's aim "to have a large number of values in common" (1916, p. 84). Ready access to this research could better equip people, whether educators, reporters, parents, or politicians, to publicly challenge comforting myths and assumptions, while providing missing evidence, histories, and ideas that may inspire a

\footnotetext{
${ }^{16}$ See Katharyne Mitchell (2001) on the "the limits of Deweyean liberalism," as she explores "the potential for educating students for democracy in a non-nationalist framework" (p. 71, original emphasis); Author (in press) on the educational limits of nationalism; and the Council of Europe (1999) which has linked democratic citizenship with social cohesion, addressing issues of exclusion in the fields of housing, health, social protection and education, and calling for a coherent rather than a homogeneous whole.

${ }^{17}$ Dewey's sense of a democratic people possessing "a large number of values in common" (1916, p. 84) was not particularly sensitive to the recent influx of immigrants of the previous decades, nor to communities that fell outside such sharing, such as Native Americans, whose unqualified citizenship was only achieved in 1924, with full voting rights not guaranteed until 1970. Compare Dewey's repeated contrasts of the "savage" with the civilized in thinking about democracy to the Native American influence on Rousseau's thinking about democracy and the possibilities of cooperative living (Sioui, 1992). Also see, Anthea Taylor (1996) on democratic education's insensitivities to Aboriginal Australians.

${ }^{18}$ I do not, however, see democratic citizens requiring "a commitment to a shared political morality," (Callan, 1997; p. 10). This "commitment" to a democratic morality, which Callan sees existing in "tension" with "the accommodation of pluralism" constrains democracy's basic liberties. In educational settings, Callan argues "it becomes rational to nourish a sense of solidarity among those who share that common status so far as solidarity makes it more likely that the relevant rights and duties are honored," to which I must add that such solidarity reduces the need to honor such rights and democracy itself (1997, p. 98).
} 
way forward. This knowledge will not resolve the disputes. If it can level the playing field at all, it will not be by dumbing things down but by providing access to a powerful source of knowledge, enabling people to explore the limits of their own and others' claims, while being able to identify the different perspectives and values at play.

Dewey writes on the final page of Democracy and Education that "all education which develops power to share effectively in social life is moral" (1916, p. 360). Can the improved access and intelligibility of educational research contribute to people's experience of such power? Is knowledge still a source of power when it is available to everyone? My argument is that we, as creators of such knowledge, should feel some obligation to take up and test such questions. We need to explore whether we are doing all that we can, in light of new technologies, to promote the democratic lifeblood of educative communication, as Dewey would have it.

Yet as I have already suggested our ideas of democracy do not stand still, and one development that has pushed Dewey's position on democracy within a pluralistic society while being especially relevant to improving the public quality of education research is the concept of "deliberative democracy" (Bohamn and Rheg, 1997; Elster 1998). For example, in Democracy and Disagreement, Amy Gutmann and Dennis Thompson step over Dewey's concern with shared values, to focus on how people can talk through and ultimately live with fundamental disagreements, by "seeking moral agreement when they can, and maintaining mutual respect when they cannot" (1996, p. 346). This attention to democracy's deliberative qualities, as opposed to its procedural or constitutional aspects, creates a civic space for social science research, whether to inform or otherwise be a part of the public articulation of issues and ideas. Gutmann and Thompson advance three principles - reciprocity, publicity, and accountability - for managing the "economy of moral disagreement" which they recognize as "a permanent condition of democratic politics" (pp. 3, 9). Each of these principles provides a further and final warrant for public-access initiatives in scholarly publishing, just as these initiatives can help us assess the public's capacity for a more deliberative democracy. ${ }^{19}$

Reciprocity, first among Gutmann and Thompson's principles, "asks us to appeal to reasons that are shared or could come to be shared by our fellow citizens" (1996, p. 14). This includes ensuring that the "empirical claims that often accompany moral arguments... be consistent with the most reliable methods of inquiry at our collective disposal" (pp. 14-15). Now, educational research is rife with reliable methods, while the differences among them, and the results which they lead to, can lead researchers at times to emulate that democratic "economy of moral disagreement." Making research public, as I have stressed, is not intended simply to resolve disagreements once and for all, although it may in rare cases. More often, the research should help clarify the probableor likely implications and consequences of people's positions. Given that deliberation leads at best to provisional conclusions, "subject to revision in light of new information and better arguments," open access to an ongoing body of research has a substantial contribution to make to these political processes (p. 356).

\footnotetext{
${ }^{19}$ The impact of "deliberative democracy" has been tested empirically by James Fishkin, who has with various collaborators "conducted fourteen Deliberative Polls in different parts of the world with random samples of respondents, brought together face to face, to deliberate for a few days. The samples have been representative of the relevant populations and they have undergone large, statistically significant changes of opinion on many policy issues" (Fiskin, 1999).
} 
Gutmann and Thompson's second and third principles - publicity and accountability - also work well with pubic access to educational research. As Gutmann and Thompson employ these concepts, publicity refers to openly sharing both the "reasons that officials and citizens give to justify political actions, and the information necessary to assess those reasons" (1996, p. 94). The scope of accountability for this deliberative process includes, for Gutmann and Thompson, a need to "address the claims of anyone who is significantly affected" by those actions (p. 129). A careful review of research results can improve the level of accountability, substantiating the claims of those who are significantly affected. ${ }^{20}$ In sum, these two political philosophers identify what I would hold up as one of the principal democratic warrants for public-access experiments with research: "Respect for [a citizen's] basic liberty to receive politically relevant information is an essential part of deliberative democracy" (p. 126).

To better prepare the public for such deliberative engagements, Gutmann and Thompson suggest that people need to learn more about how "to justify one's own actions, to criticize the actions of one's fellow citizens, and to respond to their justifications and criticisms" (p. 65). My argument, in turn, is that scholarly publishing could do more to help people turn to research, as a way of cultivating such critical reasoning abilities, although it will also fall to the schools to teach new lessons on locating and drawing on intellectual resources that best serve these processes of justification and criticism. Although this is not the place to develop the curricular benefits for the schools of going public with social science research, I would follow Jay Lemke, who in the Web's earliest days spotted the educational potential of having students pursue this more democratic approach to the larger world of knowledge, as opposed to staying within the confines of the textbook (1994). At this point, I only ask whether we could do more with our research to demonstrate a greater continuity between the democratic theory and practice of the institutions for which we are responsible. What is at stake in such a link is the most commonplace of democratic assumptions, namely that education is necessary for its advancement.

\section{Education, Research, and Democracy}

It may seem obvious enough that people need a certain level of formal education to participate effectively in a modern democratic state. Certainly, the pertinent research points to how education makes a difference, although if you look closely those with only seven years of education in America (albeit a small proportion of the population) are more active voters than all but those with 18 years of schooling (Nie, Junn, and StehlikBarry, 1996, p. 16). And while American post-secondary education attendance doubled in the quarter-century after the Second World War, the proportion of people who voted declined in that period, especially since the 1960s (p. 99). Equally so, public primary schooling in developing countries increases the chances of democracy taking hold, while secondary education does not (Kamens, 1988).

What is it about education, then, that is sufficient and necessary for democracy? What the political science research team of Nie, Junn, and Stehlik-Barry found, for example, was that formal schooling encourages people to believe "that their fate is

\footnotetext{
${ }^{20}$ This is not to discount what Gutmann and Thompson identify as publicity's amusement factor, first noted by Jeremy Bentham, that comes of people coming to know enough to catch out public officials (Gutmann and Thompson, 1996, p. 97).
} 
controlled in fundamental ways by the actions and policies of democratic governments" and that "the goals of fairness and equality are important to the long-term stability of the democratic system" (1996, p. 19). Education can predict the degree of political participation because education situates people within "politically important social networks" that offer "proximity to those who make policy decisions" and "accessibility to sources of relevant political information" (p. 45).

If that is indeed the case, then educational researchers may have it within their power to at least increase public accessibility to one source of potentially relevant political information. I would not want to exaggerate the political clout of this research. Coming to the table with a handful of pertinent studies hardly compares to old-boy networks and school-tie connections. But those lingering traditions provide reason enough, I feel, for researchers committed to this close connection between democracy and education to support the development of a public information resource to which people, as well as the organizations and agencies that would represent their interests, have equal access.

There are, however, two common assumptions about the public role of research that this open access approach challenges. The first is that research is best summarized, translated, and synthesized before being made public. It needs to have the wrinkles and disputes cleared away, so that it can present a singular, definitive answer to pressing questions. This mediated approach to preparing research for public consumption has been the tack, for example, of the American Educational Research Association's outreach activities and the National Research Council consensus panels. ${ }^{21}$ Yet, we should not assume that the public cannot bear the complexities of current educational research, given how we have learned to live, for example, with the lack of definitive scientific studies on the effectiveness of screening tests for cancer. Greater public familiarity with the discrepancies and disagreements that mark an ongoing body of research will act as a check on the temptation to bring in the experts to resolve social issues, effectively removing those issues from the democratic sphere of deliberation. It will also help people see that disagreements among scientists often reflect conflicts in values within the larger society, again suggesting that science does not somehow stand outside of the democratic sphere (Fischer, 2000, p. 64).

A democracy would seem to demand direct access to public relevant and credible sources of knowledge, even as those sources are recognized as shaped by their own democratic differences in values and judgments. It may well be that enhancing public access to this knowledge will also prove a boon for inspiring faculty and students to give greater thought to writing for this expanded audience, taking the time to explain themselves in a way that will reward their work with a greater impact thanit has previously had a chance of achieving. This openness may well prove a source of insight into the intricate links between the public and scholarly forces that drive research within a public sphere like the schools.

The second common assumption about education research in particular which this open access approach challenges, is that the way to enhance its public status is to focus it more systematically on improving school practices, as recent proposals by the National Research Council (1999) and National Academy of Education (1999) recommend

\footnotetext{
${ }^{21}$ The National Research Council seeks "to have a positive influence on public policy and to increase public awareness of scientific, technical, and medical issues" (Choppin and Dinneen, 2000, p. 34).
} 
(Willinsky, 2001a). This may end up doing less for the democratic quality of our lives, as research is used to fine tune teaching procedures and school programs, while offering less to contribute to what people think about education in a larger sense. The educational contribution that research can make to democracy is far more about providing, for example, the historical contexts of long-standing school issues, posing challenges to people's basic thinking about learning, envisioning radical alternatives to current programs, and otherwise becoming a part of how people think about what schools can and should do. There is certainly a place for research directed at improving teaching practices within the scope of certain standardized tests, but I think that many researchers would be rightly apprehensive about going public with their work if it means that the immediate applicability of research becomes the principal and most prized aspect of our work as intellectuals.

In arguing for improving public access to education research, I recognize that one of the educational issues that we will need to face is bringing the public in on the very scope and diversity of research. Yet I cannot help but think that to encourage this broader awareness of what schooling is about is itself educationally enriching in a public sense. In thinking about how children should be educated, whether in making personal, professional, or policy decisions, people should be able to find ways of getting close to the daily life of the classroom, in ways that researchers have, as well as gain an overview of how students in their nation are performing on international assessments. People would do well to discover how a science student learns to make ethical decisions, just as they need to know whether girls have an equal opportunity to be scientists. They also need a framework for thinking about school choice and public education in terms larger than current instructional efficacy comparisons. AERA's motto - "Research Improves Education" - seems to me to unnecessarily limit what research can help us know. The organization would be better served, given what I have argued here, by a motto closer to "Research Informs Education."

It is not, of course, that I imagine everyone using this research on anything like a daily basis, although new work on evidence-based practices in medicine and other forms of professional practice would suggest it could have a regular role to play. ${ }^{22}$ Far more often, this engagement with research will be a matter of personal interests, pressing public issues, and passing curiosities. Still, we should not underestimate the difference that this occasional interest can make. When the public has turned to research, as citizen groups have around environmental issues, for example, they are "not necessarily hostile to technical data," political scientist Frank Fischer has found in his study of citizen action groups, especially if that data is "presented and discussed in an open democratic process" (2000, p. 130). Although members of these groups may initially have found it hard to even speak with researchers, before long these concerned citizens were actively involved in the research process itself, giving rise to, for example, "popular epidemiology" in which the public helps to track the distribution of diseases (pp. 151-157). The instance of a researcher-public alliance forming around environmental issues suggests how local and expert knowledge can play a critical part in these deliberative processes: "Instead of questioning the citizen's ability to participate, we must ask," Fischer insists, "how can we interconnect and coordinate the different but inherently interdependent discourses of citizens and experts" (2000, p. 45). He calls for a reconstructed concept of professional

${ }^{22}$ On the prospects of evidence-based practice for education, see Willinsky (2001b) 
practice among researchers whose task is "authorizing space for critical discourse among competing knowledges, both theoretical and local, formal and informal" (p. 27). Such are the goals for scholarly publishing publicly accessible.

Perhaps the most dramatic lesson of how the educational benefits of this public engagement works for both the public and science can be drawn from the AIDS activists of the 1980s and 1990s. As Steven Epstein tells it in Impure Science (1996), these activists successfully struggled for public participation in medical knowledge, which meant, among other things, bringing otherwise overlooked research into the limelight and changing the conduct of clinical trials. Scientists found themselves moved by activists in both an intellectual and ethical sense, while activists "imbibed and appropriated the languages and cultures of biomedical sciences," acquiring their own forms of credibility in public and scientific deliberations over how to respond to AIDS by "yoking together moral (or political) arguments and methodological (epistemological) arguments" (pp. 335-56).The AIDS struggle established the need for, in the words of ACT-UP activist Mark Harrington, "a lasting culture of information, advocacy, intervention, and resistance" (p. 350). The lesson drawn from the fight against this tragic pandemic that is no less with us today, is that enabling people to play a greater part in directing their own lives amid a complex crisis can lead to better science and an extension of the democratic sphere.

The public place of research also needs to be seen on a global scale, where disparities in educational opportunities, and access to knowledge more generally, are greatest. Avinish Persaud, of the State Street Bank in Boston, holds that the current knowledge economy is only increasing the gap between rich and poor nations - a knowledge gap that he calculates (based on number of scientists) to be ten times the income gap. He asks us to imagine the discrepancies between an imagined economist in Iowa, tapping into "thousands of journals on-line" as well as news services and other resources, while "many researchers in developing countries lack this opportunity" as do “civil servants who wish to explore policy options" (2001, pp. 109-110).

The problem is not simply a lack of phone-lines and computers. The gap between haves and have-nots is just as much a matter of access to well organized sources of knowledge. Consider, for example, how critical open-access to an e-journal such as the British Medical Journal is to the University of Zimbabwe, which has had to slash its journal subscriptions from 600 to 170 due to rapidly escalating subscription costs. It "has won our hearts because it is free," reports the university's medical librarian (Nagourney, 2001). A number of scholarly societies have found it easy enough to grant open access to developing nations for their electronic editions. And even the the six major commercial publishers of academic journals, otherwise accused of provoking the crisis in scholarly publishing with their price increases over the last decade (ARL, 2000), have recently announced that they will make 1,000 of the world's top 1,240 medical journals free or deeply discounted for developing countries (Peterson, 2001).

As scholars, we appear to now have it within our power to share our knowledge with the larger world of students, teachers and policy-makers. We need to think about how we, as educational researchers, could give more back to education. What we might well find is that the increased scale of this give and take, between public and researchers on an international scale, could well influence how we work and write in response to the increased educational and democratic value of this knowledge for people everywhere. 
Historian Ellen Condliffe Lagemann (2000) has identified educational research as "an elusive science," as a way of pointing to researchers' frustrated pursuit of scientific ideals and academic respectability. She claims that, "Since the earliest days of university sponsorship, education research has been demeaned by scholars in other fields, ignored by practitioners, and alternatively spoofed and criticized by politicians, policy makers and members of the public at large" (p. 232). She concludes that what is needed is more systematic planning of research agendas in education, as well as a means of "reconciling the differences that inevitably arise as scholars study such difficult, complex problems" (pp. 240-241). I am suggesting that one way to improve the research agenda is to make the whole research process more open and public, as well as better connected and easier to track, all of which would, in turn, help researchers and the public work together at identifying priorities, opportunities, and gaps in what we know about education. This would be consistent with Lagemann's critical suggestion that "scholars of education might also more commonly come to acknowledge their responsibility to educate the public about education and about education research" (2000, pp. xiii, 245).

\section{Media, Research, and Democracy}

To move academic research more thoroughly into the public domain is to create a substantial alternative source of public information. Democracies have typically relied on a free press to create an informed electorate and an informed governing body, or as Thomas Jefferson put it in a letter in 1787 to Edward Carrington: "The basis of our governments being the opinion of the people, the very first object should be to keep that right and were it left to me to decide whether we should have a government without newspapers or newspapers without a government, I should not hesitate a moment to prefer the latter. But I should mean that every man should receive those papers and be capable of reading them" (1997). In thinking about making this body of research more widely available, we have lessons and inspiration to draw from the earlier political role of an emerging periodical press, and the printing press more generally. The United States' "Enlightenment" during those years was driven by a "technology of publicity," in historian Michael Warner's estimation, a technology rendered "civic and emancipatory" by Thomas Paine, Benjamin Franklin, and other of the day's determined democrats (1990, p. 3).

Beginning in seventeenth-century Europe, the daring and steady stream of pamphlets, broadsides, and newsletters, amid the risks of state censorship, forged a new sense of public voice, interest, and energy. As historian David Zaret (2000) observes, "practical innovations in political communication preceded and prepared the way for democratic principles" (p. 270). Zaret also makes it clear that for democratic theories and revolutions, these "practical innovations" needed to be combined with a John Locke's "liberal confidence in the capacity for individual self-help and reason" (pp. 275, 270). Print fostered a market whose political force defined what we now call the public opinion.

I turn, if ever so briefly, to the press' golden past because the democratic spirit of that age, with its practical innovation and liberal confidence, corresponds far more closely to what inspires this move for open access to scholarship than is reflected in the current state of the press. Today, the media's democratic force strikes many as dissipated, if not lost completely. Ben H. Bagdikian (2000), the former School of Journalism Dean at 
the University of California Berkeley, finds that the emancipatory press of yesteryear has been reduced largely through corporate concentration to "trivialized and self-serving commercialized news," in estimation (p. ix). In the preface to the sixth edition of Media Monopoly, Bagdikian observes that "power over the American mass media is flowing to the top with such devouring speed that it exceeds even the accelerated consolidations of the last twenty years" (2000, p. viii). Not only do a handful of mega-corporations control "the country's most widespread news, commentary and daily entertainment," but these conglomerates have "achieved alarming success in writing the media laws and regulations in favor of their own corporations and against the interests of the general public" (2000, p. viii). ${ }^{23}$ I interpret this disenchantment with the press as democracy's great hope to be a further warrant, not surprisingly, for testing whether social science research, which is no less dedicated to the public interest, might offer a substantial and reliable alternative or supplementary source of systematic inquiry and information. ${ }^{24}$

At this point, the relationship between press and research remains uneasy in ways that suggest that neither feels all that well served by the other. It is common to find researchers, such as Christopher Forrest, a professor of pediatrics and health policy at Johns Hopkins University, accuse the press of, in effect, supporting public shortsightedness, or as Forrest puts it: "The public reads the bottom line. They act on that without putting the study into context. In politics, there is always a context. The same is true for science, but it doesn't get reported that way" (quoted in Stolberg, 2001; p WK3). The press is not above hitting back at researchers, as Sheryl Gay Stolberg, the reporter who cited Forrest, responded that, "we live in a dizzying world, where scientists produce a stream of research, and each new study seems to contradict the previous one" (Stolberg, 2001; p WK3).

The problem here may indeed be that the context for interpreting science goes missing, as Forrest points out, but then we do little enough to help reporters or the public establish even the most basic context or background for any given study. . This was fine as long as the research was taking place far away from public eyes, where only an intrepid reporter might venture, interrupting the researcher long enough to get a snappy quote or soundbite. If we begin to think about research as part of the public record, financed as so much of it is by public money, then suddenly our relationship to the larger world shifts as we become responsible for a source of public knowledge. What this greater access to research could mean, as I have been describing it, is providing a context for our work, a technology enabled context in which reporters and readers can readily turn to related studies, overviews, policies and programs, that would make clear how contradictions play out in this difficult work with knowledge. This would improve the

\footnotetext{
${ }^{23}$ Bagdikian is hardly alone in his critique of the press' declining democratic contribution, and in addition to well-known media gadfly Chomsky, (e.g., 1998) and the already cited McChesney (1999), see Cappella and Jamieson (1997), Iyengar (1991), Page, (1996), and Schiller (1996). The big seven media corporations, as I write, are AOL Time Warner, Bertelsmann, Walt Disney, the News Corporation, Sony, Viacom and Vivendi, with a combined revenue of $\$ 153$ billion for 2001, and a collective market share of, for example, $80 \%$ in U.S. book publishing by revenue (Schiesel, 2002).

${ }^{24}$ In support of that supplementary approach, the Public Knowledge Project ran a week-long research support website with a local newspaper which allowed readers to tap into a database of links to research studies related to the paper's series on technology and education, as well as join discussion forums with researchers and view pertinent teaching materials, policies, and organizations. See "Prototypes" at the Public Knowledge Project (http://pkp.ubc.ca).
} 
press' coverage of research, but perhaps more importantly, given that scholarship's methodical pursuit of knowledge is not well suited to the fast-news fare of today's media, it would enable readers to move from press coverage to the study itself, enabling them to travel as far as they wish into research's realm.. ${ }^{25}$

The final argument to be made for ensuring that research stands alongside the media as a public source of information comes from the apparent electronic future of the press, which poses its own threat to the press' traditional service to democracy. Legal scholar Cass Sunstein (2001) has perceptively warned that the Internet is being used to create what might be thought of as gated information-communities. Readers can personalize the news that crosses their sceens, pre-selecting topics and sources, which makes them less readers of the news and more of info-consumers, "able to see exactly what they want to see" (Sunstein 2001; p. 5). He holds to the basic democratic principle that "people should be exposed to materials that they would not have chosen in advance. Unplanned, unanticipated encounters are central to democracy itself” (p. 8). Although he affirms, much like Dewey, the importance of citizens having common experiences, which I addressed above, the educational quality of "unplanned, unanticipated encounters" with information, which he sees as critical to democracy, is very close to the heart of the proposal under consideration here. People within a community may have far fewer media experiences in common than they did in the past, but one advantage of this increasing variety is that it may well draw citizens into comparing where they turn for information and entertainment, all of which hardly weakens, I would think, the ties that bind democracy to education.

Still, Sunstein offers a healthy caution for an open access project that is set on improving public access to educational research. If it is going to steer clear of a narrowly cast information consumerism, in its efforts to improve the scholarly quality of that engagement, then public-access systems will need to ensure that contrary and critical commentary are within a click or so of the work that it challenges, just as related work from abroad needs to sit near domestic studies, to keep the parochialism at bay. Contrary viewpoints can still be ignored, of course, but a little less easily, perhaps, and certainly it is more difficult to deny their existence when they loom but a click or two away. The very availability of information in a democracy, whether people attend to it or not, Sunstein holds, "increases the likelihood that government will actually be serving people's interests," or as Sunstein cites Justice Louis Brandeis holding, "sunlight is the best of disinfectants" (2001, pp. 90, 176). ${ }^{26}$

If the measure of a democracy is not to be gauged by how many take up this public knowledge or how often they turn to it, the ready availability of this knowledge can still be said to contribute to the educational and communicative qualities of its citizens' lives together. Like the public libraries that can be found in the smallest of communities, no less than the newspapers of the smallest town, the presence and possibilities of being able to turn to a given body of knowledge exerts its own force of

\footnotetext{
${ }^{25}$ Todd Gitlin (1980) addresses these issues head-on when he speaks of the press' focus on "the novel event, not the underlying, enduring condition; the person, not the group; the visible conflict, not the deep consensus; the face that advances the story, not the one that explains or enlarges it" (p. 263).

${ }^{26}$ Sunstein also holds that the "absence of the demand [to see some form of information on the part of the people] is likely to be the product of the deprivation," which I would suggest that we at least test in the case of educational research (2001, p. 111).
} 
reasonableness and reassurance. Here, then, is our chance as educators and knowledge workers of some sophistication to extend the vital force of the media as a source of greater awareness and understanding, as well as to supplement if not challenge its particular framing of what can be known of the world.

\section{Final Remarks}

One encouraging bit of news in education over the last few years has been a few signs that the notorious theory-practice gap is narrowing. Gloria Ladson-Billings (1995) commends researchers for their "willingness to listen and learn from practitioners [which] is providing researchers and teacher educators with opportunities to build a knowledge base in conjunction and collaboration with teachers" (p. 755). With this growing knowledge base in hand, now would seem a time for researchers to give more back to teachers by opening that collaboratively developed knowledge to public and professionals alike. The concern for reciprocity should inspire researchers to pursue new systems of scholarly communication that strengthen the public dimensions of this collaborative spirit. Otherwise, it may turn out that these new technologies for scholarship end up serving little more than the immediate interests of researchers, and as such prove yet another boon for well-financed universities, leaving the rest of the world further behind.

The preferred goal that lies ahead, as I have outlined here, is the design and development of systems that address both the public and scholarly quality of our research activities. There is no way of predicting how new media will massage old messages, but we can reasonably expect both public discourse and educational research to be altered. Thus, my interest, as an educator and student of literacy, is in treating these new systems as experiments in how knowledge can extend its contribution within a democratic and educational culture, a culture that has room to grow, one hopes, as part of a larger global society. These experiments are best seen as part of a long and often difficult history in the spreading and sharing, challenging and augmenting, of ideas. As such, it would not be wise to deny the risks associated with such experiments in the history of ideas.

In asking researchers, journal editors and scholarly associations to give, as it were, their informed consent before participating in publishing experiments aimed at improving public access to education research, it is only fair to acknowledge the risks this might entail. These publishing experiments may lead to momentary vertigo, induced by uncertainties over career impact and prestige risk. These new publishing systems will clearly need to be as sensitive to the career aspirations of contributors, as to their desire to see this earnest pursuit of a knowledge have a larger impact in a global exchange of ideas. Fortunately, the early indications from studies of the impact of e-journals are encouraging for career concerns. ${ }^{27}$ These experiments may also cause professional associations temporary consternation, over the prospects of seemingly irrelevant and irreverent questions being raised about research directions and practices from a newly informed public. Similarly, journal editors may also worry for the academic freedom of

\footnotetext{
${ }^{27}$ Anderson, Sack, Krauss, and O'Keefe (2001) found that free online refereed publications are cited as often as traditional print and slightly more than closely related studies in the same area, and that these open access publications were felt by faculty to fully count for tenure. Steven Lawrence (2001) found in a study of 119,924 conference articles in computer science that more highly cited articles are more likely to be freely available online.
} 
their authors, now that the refuge of inaccessibility will no longer be the great protector of that freedom. It will, however, be that much easier to defend the fruits of academic freedom by being able to present where a single study fits within the larger context of scholarly inquiry. So, too, can this openness foster greater public support for research, one would hope, within an atmosphere of open discussion about the range and scope of academic inquiry.

Given the power of these new technological resources to make resources readily available, something seems terribly amiss for people to have so little public access to the work of so many scholars. How is it that we have such a substantial body of knowledge that lies beyond the reach of public life and political forums, private lives and educational institutions? This world of knowing needs to be transformed into a public resource, if only as an alternative to what can otherwise seem like a singular stream of media confluence coursing through some 500 television channels. If nothing else, this open access to research resources will put common assumptions about the value of this knowledge, whether among the public or researchers, politicians or teachers, to the test.

Given the innovative and experimental nature of this publishing environment, it becomes important to test these assumptions, by assessing the impact, across a range of measures, of open access scholarly publishing systems on the public, professionals, and policy officials (as well as on progress of academic careers). Our own research plans include asking whether and how the design of these open access publishing systems contribute to people's ability to consult pertinent research evidence in decision making, to critically evaluate sources of educational information, to link educational practices to related theories, and to place educational issues within a historical perspective. It also seems important to know if the availability of this research supports people's participation in civic and educational forums, increases their interests in collaborating with the research community, or expands their appreciation of how research works. Then, there is the question of how this increased access to a wide range of scholarly resources, from data sets to dissertations, adds to the rigor and reliability of peer review processes, just as increased public engagement may work on the direction, design, and writing of research. If there are gains in any of these areas, they will be modest, at best, but all of them are worth pursuing, if only for what such inquiries can tell us about learning and knowledge in this new information environment, as well as about the nature of our own work.

Many of the details of creating a more accessible public space for knowledge have still to be worked out, in a similar process to the one public libraries faced in the past, as they set out to overcome the public's limited access to print over the last two centuries through a number of successful strategies. We have only to imagine how to take the next step in creating places to which people can turn, however rarely or infrequently, when they are taken by the urge to go deep and far into existing bodies of knowledge. We have also to realize that going public with our research will gradually change how we conduct our studies in and outside of schools, how we write about and connect our work to other studies, as well as to larger and local worlds of information. In this way, new publishing and broadcasting systems seem bound to reshape both democracy and education, strengthening the link between them. Or at least, I have argued the reasons why we are under some obligation to test such propositions. Let the democratic experiment continue. 


\section{Acknowledgements}

I would like to thank Anne White and the editors of this journal for their assistance with this article, as well as the Social Science and Humanities Research Council of Canada and the Max Bell Foundation for their support of this work.

\section{References}

Alexander, C. J. and Pal, L. A. (Eds.). (1998). Digital democracy: Policy and Politics in the Wired World. Toronto ON: Oxford University Press.

Anderson, K., Sack, J., Krauss, L., and O'Keefe, L. ( 2001). Publishing online-only peerreviewed biomedical literature: Three years of citation, author perception, and usage experience. Journal of Electronic Publishing, 6(3). Retrieved April 30, 2002, from http://www.press.umich.edu/jep/06-03/anderson.html.

Arms, W. Y. (2000). Economic models for open access publishing. IMP: The Magazine on Information Impacts. Retrieved April 30, 2002, from http://www.cisp.org/imp/march_2000/03_00arms.htm.

Association of Research Libraries (ARL). (2000). Scholars under siege [web-page], Available at: http://www.arl.org/create/librarians/issues/silent.html\#WhereNow.

Bagdikian, B. H. (2000). The media monopoly (6th Ed). Boston: Beacon.

Bailey, C.W., Jr. (1996-2001). Scholarly Electronic Publishing Bibliography. Houston: University of Houston Libraries. Retrieved April 30, 2002, from http://info.lib.uh.edu/sepb/sepb.html.

Bohman, J. \& Rheg, W. (Eds.). (1996). Deliberative democracy: Essays on reason and politics. Cambridge, MA: MIT Press.

Bowen, W. G. \& Bok, D. (1998). The shape of the river: Long-term consequences of considering race in college and university admissions. Princeton, NJ: Princeton University Press.

Callan, E. (1997). Creating citizens: Political education and Liberal democracy. Oxford, UK: Oxford University Press.

Cameron, R. D. (1997). A Universal Citation Database as a catalyst for reform in scholarly communication. First Monday, 2(4). Retrieved April 30, 2002, from http://www.firstmonday.dk/issues/issue2_4/cameron/.

Cappella, J. N. and Jamieson, K. H. (1997). Spiral of cynicism: The press and the public good. New York: Oxford University Press.

Chomsky. N. (1998). Propaganda and the control of the public mind. In Eds. R. W. McChesney, E. M. Wood, and J. B. Foster, Capitalism and the Information Age: The political economy and the global communication revolution (pp. 180-181).

New York: Monthly Press.

Choppin, P.W. \& Dinneen. G. P. (2000). The NRC in the 21st century: Report of the task force on NRC goals and operations. Washington, DC: National Research Council. Retrieved April 30, 2002, from http://www.nationalacademies.org/about/pdfs/taskforce.pdf.

Congress struggles with flood of e-mail. (2001, March 4). New York Times, p. A16.

Cuban, L. (2001). Oversold and Underused : Computers in Classrooms. Cambridge, MA: Harvard University Press.

Cuban, L. (1986). Teachers and Machines : The Classroom Use of Technology Since 1920. New York: Teachers College Press. 
De Tocqueville, A. (1969). Democracy in America (Trans. G. Lawrence). New York: Doubleday.

Dewey, J. (1916). Democracy and education. New York: Macmillan.

Dewey, J. (1938). Education and experience. New York: Macmillan.

Dewey, J. (1988a). The public and its problems. In The later works, 1925-1953 (Vol. 2: 1925-1927). (Ed. J. A. Boydston). Cabrondale, Il: Southern Illinois University Press.

Dewey, J. (1988b). The quest for certainty. In The later works (Vol. 4: 1929). (Ed. J. A. Boydston). Carbondale, IL: Southern Illinois University Press.

Dworkin, R. (2001, April 13). Race and the use of law. New York Times, p. A19.

Elster, J. (Ed.). (1998). Deliberative democracy. Cambridge, UK: Cambridge University Press.

Epstein, S. (1996). Impure science: AIDS, activism, and the politics of knowledge. Berkeley, CA: University of California Press.

Fischer, F. (2000). Citizens, experts and the environment: The politics of local knowledge. Chapel Hill, NC: Duke University Press,

Fishkin, J. S. (1999). Deliberative polling as a model for ICANN membership. Unpublished paper, Berkman Center for Internet \& Society at Harvard Law School. Retrieved April 30, 2002, from http://cyber.law.harvard.edu/rcs/fish.html.

Freudenheim, M. (2000, May 30). New web sites altering visits to patients. New York Times, pp. A1, C14.

Gitlin, T. (1980). The whole world is watching: Mass media in the making and unmaking of the new left. Berkeley, CA: University California Press.

Gutmann, A. and Thompson, D. (1996). Democracy and disagreement. Cambridge, MA: Harvard University Press.

Hague, B. N. and Loader, B. D., Eds. (1999). Digital democracy: Discourse and decision making in the information age. London: Routledge.

Heek, R., Ed. (1999). Reinventing government in the information age: International practices in IT enabled public sector reform. London: Routledge.

Himmelfarb, G. (1995). On looking into the abyss : Untimely thoughts on culture and society. New York: Vintage Books.

Iyengar, S. (1991). Is anyone responsible: How television frames political issues. Chicago, IL: University of Chicago Press.

Jefferson, T. (1997). Letter of Thomas Jefferson to Edward Carrington, 1787. The Letters of Thomas Jefferson: 1743-1826. Groningen, Netherlands: Humanities Computing. Retrieved April 30, 2002, from http://odur.let.rug.nl/ usa/P/tj3/writings/brf/jefl52.htm.

Kamens, D. H. (1988). Education and democracy: A comparative institutional analysis. Sociology of Education, 61, 114-127.

Ladson-Billings, G. (1995). Multicultural teacher education: Research, practice, and policy. In J. A. Banks \& C. A. McGee Banks, Handbook of research on multicultural education ( pp. 747-759). (ERIC Document Reproduction Service No. ED 382 738). New York: Macmillan.

Lagemann, E. C. (2000). An elusive science: The troubling history of education research. Chicago: University of Chicago Press. 
Lawrence, S. (2001). Online or invisible? Nature, 411(6837), 521. Retrieved April 30, 2002, from http://www.neci.nec.com/ lawrence/papers/online-nature01/.

Lawrence, S., Giles, L. C., and Bollacker, K. (1999). Digital libraries and autonomous citation indexing. IEEE Computer, 32 (6), 67-71. Retrieved April 30, 2002, from http://www.neci.nec.com/ lawrence/papers/aci-computer99/

Lemke, J. (1994). The coming paradigm wars in education: Curriculum vs. information access." In Cyberspace Superhighways: Access, Ethics, and Control, Proceedings of the Fourth Conference on Computers, Freedom, and Privacy (pp.76-85).

Chicago: John Marshall Law School. Retrieved April 30, 2002, from http://academic.brooklyn.cuny.edu/education/jlemke/papers/cfppaper.htm.

Lincoln, A. (1861, July 4). Message to Congress. In The Official Records of the Union and Confederate Armies, Series IV, I, 311-321, p. 35. Retrieved April 30, 2002, from http://www.furman.edu/ benson/docs/lincoln.htm.

Lippmann, W. (1963a). The public and its role. In The essential Lippmann: A political philosophy for liberal democracy (pp. 85-125). New York: Random House.

Lippmann, W. (1963b). The dilemma of liberal democracy, in The essential Lippmann: A political philosophy for liberal democracy (pp. 3-26) New York: Random House.

Macedo, S. (Ed.). (1998). Deliberative politics: Essays on Democracy and Disagreement. New York: Oxford University Press.

McChesney, R. W. (1999). Rich media, poor democracy: Communication politics in dubious times. New York: Free Press.

McKiernan, G. (2001). EJI(sm): A registry of innovative e-journal features, functionalities, and content. Ames, IA: Iowa State University Library. Retrieved April 30, 2002, from http://www.public.iastate.edu/ CYBERSTACKS/EJI.htm.

Mitchell, K. (2001). Education for democratic citizenship: Transnationalism, multiculturalism, and the limits of liberalism. Harvard Educational Review, 71(1), 51-78.

Nagourney, E. (2001, March 20). For medical journals, a new world online. New York Times, pp. 1-2.

National Academy of Education (NAE). (1999). Recommendations regarding research priorities: An advisory report to the National Educational Research and Policy and Priorities Board. New York: National Academy of Education.

National Research Council (NRC). (1999). Improving student learning: A strategic plan for educational research and its utilization. Committee on a Feasibility Study for a Strategic Educational Research Program. Washington, DC: National Academy Press.

Page, B. I. (1996). Who deliberates: Mass media in modern democracy. Chicago, IL: University of Chicago Press.

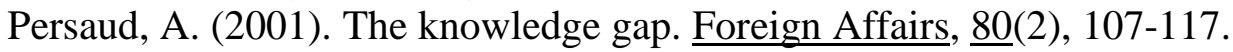

Peterson, M (2001, July 9). Medical journals to offer lower rates in poor nations, New York Times, p. A3.

Putman, R. D. (2000). Bowling alone: The collapse and revival of American community. New York: Simon and Schuster.

Ravitch, D. (2001). Left back: A century of battles over school reform. New York: Tocuhstone.

Ross, L. (2001, April 9). Dept. of Big Thoughts: The $1845^{\text {th }}$. New Yorker, p. 39. 
Schiesel, S. (2002, March 11). The media giants: Overview, the Corporate strategy. New York Times, $\mathrm{C} 1$.

Schiller, H. I. (1996). Information inequality: The deepening social crisis in America. New York: Routledge.

Schlesinger, A. (1992). The disuniting of America: Reflections on a multicultural society. New York: Norton.

Shavelson, R., Feuer, M., and Towne, L. (2001). A scientific basis for educational research? Themes and lessons from a workshop. Paper presented at AERA, Seattle.

Sioui, G. E. (1992). For an Amerindian autohistory: An essay on the foundations of a social ethic (S. Fischman, Trans.). Montreal: McGill-Queens University Press.

Stolberg, S. G. (2001, April 22). Science, studies and motherhood. New York Times, p. WK3.

Sunstein, C. R. (2001). Republic.com. Princeton, NJ: Princeton University Press.

Taylor, A. (1996). Education for democracy: Assimilation or emancipation for Aboriginal Australians. Comparative Education Review, 40(4), 426-438.

Warner, M. (1990). The letters of the republic: Publication and the public sphere in eighteenth-century America. Cambridge, MA: Harvard University Press.

Wilhelm, A. G. (2000). Democracy in a digital age: Challenges to political life in cyberspace. New York: Routledge.

Willinsky, J. (2001a). The Strategic Education Research Program and the public value of research. Educational Researcher, 30(1), 5-14. Retrieved April 30, 2002, from http://www.aera.net/pubs/er/toc/er3001.htm.

Willinsky, J. (2001). Extending the prospects of evidence-based education. IN $>>$ SIGHT, 1(1), 23-41. Retrieved April 30, 2002, from http://pkp.ubc.ca/publications/evidedu.htm.

Willinsky, J.(2000a). Proposing a Knowledge Exchange Model for Scholarly Publishing. Current Issues in Education, 3(6). Retrieved April 30, 2002, from http://cie.ed.asu.edu/volume3/number6/.

Willinsky, J. (2000b). If only we knew: Increasing the public value of social science research. New York: Routledge.

Willinsky, J. \& Wolfson, L. (2001). The indexing of scholarly journals: A tipping point for publishing reform? Journal of Electronic Publishing, 7(2). Retrieved April 30, 2002, from http://www.press.umich.edu/jep/.

Zaret, D. (2000). Origins of democratic culture: Printing, petitions, and the public sphere in early modern England. Princeton, NJ: Princeton University Press. 